\title{
Learning Electrical Circuits: The Effects of the 4C-ID Instructional Approach in the Acquisition and Transfer of Knowledge
}

\author{
Mário Melo and Guilhermina Lobato Miranda \\ Institute of Education, Lisbon University, Lisbon, Portugal
}

\author{
mmlmelo@hotmail.com gmiranda@ie.ulisboa.pt
}

\begin{abstract}
This study was designed to investigate the effects of two instructional approaches (4C-ID versus conventional) on learners' knowledge-acquisition and learning transfer of the electrical circuits content in Physics. Participants were $1299^{\text {th }}$ graders from a secondary school in Lisbon, $M=14.3$ years, $\mathrm{SD}=0.54$. The participants were divided in two groups: an experimental group constituted three intact classes $(n=78)$; and a control group constituted two intact classes $(n=51)$. The experimental group was taught using a digital learning environment designed with the 4C-ID model principles while the control group learned the same contents through a conventional method. We assessed the students' performance (knowledge-acquisition and transfer), the perceived cognitive load, and the instructional efficiency. Results indicated that the experimental group performed significantly better than the control group on a knowledge-acquisition test and in a learning transfer test. They also perceived a less cognitive load in the transfer test and the learning environment developed with the 4C-ID model proved to be more instructional efficient than the conventional method.
\end{abstract}

Keywords: 4C-ID model, complex learning, electrical circuits, learning tasks, learning transfer

\section{Introduction}

A major goal of schooling is to prepare students for flexible adaptation to new problems and settings. The psychologist Robert Gagné (1970) states that the capabilities learned in school must provide students with the background and skills to accomplish things in their personal and professional lives. This would be more easily achieved if educational programs were developed to train the ability to transfer what students learn in one context to other contexts.

However, while transfer is a key component of learning and appears to be a natural process, experimental research has shown that it is not a spontaneous phenomenon and it is difficult to put into evidence (cf. Bassok, 1990; Gick \&

Material published as part of this publication, either on-line or in print, is copyrighted by the Informing Science Institute. Permission to make digital or paper copy of part or all of these works for personal or classroom use is granted without fee provided that the copies are not made or distributed for profit or commercial advantage AND that copies 1) bear this notice in full and 2) give the full citation on the first page. It is permissible to abstract these works so long as credit is given. To copy in all other cases or to republish or to post on a server or to redistribute to lists requires specific permission and payment of a fee. Contact Publisher@InformingScience.org to request redistribution permission.
Holyoak, 1983), especially when the tasks to be learned are complex, as are most of the ones learned in school (Perkins \& Salomon, 1992; Resnick \& Collins, 1996; Salomon \& Perkins, 1989). It is relevant to clarify that a complex task involves a complex learning, which includes the integration of knowledge, skills and attitudes. The term complex should not assign the connotation of 
complicated or difficult, since these concepts involve performing tasks with difficult resolution, while the concept complex, in the context of learning, refers to the integration of acquired (and new) knowledge, skills and attitudes about a particular area of study (e.g. sciences, information technology, law, etc.) (cf. Sweller, Ayres, \& Kalyuga, 2011). This does not mean that these complex tasks are difficult to solve. The complexity of a task emerges from the components students must integrate and not from something that is difficult to do, understand, or deal with.

The concept of transfer of learning, which emerged in the context of the first experimental studies on animal and basic human learning (cf. Pavlov, 2003/1927; Skinner, 1965/1953) and also in school learning (cf. Thorndike \& Woodworth, 1901), was not consensual (cf. Dewey, 1916) and continues not to be so (cf. Greeno, 1997; Packer, 2001).

In the early twentieth century, Thorndike and Woodworth (1901) developed the 'theory of identical elements,' which stated that what was transferred were specific facts and skills and not general principles, and this only occurs when the situation to which it is applied is similar to the initial learning context. Dewey (1916) states this concept has little or even no utility to school learning, a position that is agreed upon today by the contextual or situated approach to learning and cognition (cf. Greeno, 1997; Greeno, Collins, \& Resnick, 1996; Lave \& Wenger, 1995; Rogoff \& Chavajay, 1995).

The concept of similarity also turned out to be more complex than it was supposed to be by the time of Thorndike and Woodworth (cf. Smith, 1993; Vosniadou \& Ortony, 1989). When do we say that two tasks or problems are similar? When they have identical surface characteristics or when they have identical solution schemas? Research in cognitive psychology has shown that the novices in a given knowledge domain (chess, Physics or Mathematics) considered that two problems are identical when they have similar surface characteristics; on the contrary, experts classify them according to the solution schemes (Bransford, Brown and Cocking, 2000; Chi, Glaser, \& Rees, 1982; Simon, 1982).

Learning is, to this framework (Anderson, 1983), the acquisition and compilation of mental schemas, some of which have become automatic. It is useful to the human being to acquire automatic processes, but it is also very important to develop a conscious control of mental processes and an analytical knowledge, which are present in complex learning (cf. Salomon \& Perkins, 1989) and in the upper unique physiological processes of the human species (cf. Vygotsky, 1984).

Salomon and Perkins (1989) refer two kinds of transfer: the low-road transfer and the high road transfer, and the mechanisms that promote each one: "The triggering of well-practiced routines by stimulus conditions similar to those in the learning context" (Perkins \& Salomon, 1992, par. 1) for the first one; and the 'mindful abstraction' and the search for connections for the second. People must use certain types of mental processes to reach this kind of abstraction, including representing the information in a more general sense that includes other cases. The abstraction has the form of a rule, a principle, a schematic pattern, a prototype or a category (Salomon $\&$ Perkins, 1989). And these processes must be carried out voluntarily and in a controlled manner; that is, requiring deliberate and conscious effort, typical of metacognition and deep processing (cf. Kintsch, 1977).

These research results are due to experimental studies and some of them were conducted out of natural learning contexts.

During the last decades there has also been a body of research that has shown it is possible to teach students to transfer. This requires the learning environment to be explicitly designed to promote the transfer, considering positively the two groups of variables responsible for it: one associated to the students' characteristics, and the other to the learning tasks. 
In the first case, it is advised to develop students' skills associated with metacognition (Brown, 1978, 1987; Brown \& Campione, 1981, 1986), mainly a 'deliberate effortful abstraction and a search for connections' (Perkins \& Salomon, 1992, par. 1). In the second case, it is recommended to develop tasks that promote the decontextualization of skills to be acquired.

In a simple but not simplistic way, we can say that the real problem of transfer may be in the way students acquire the skills and knowledge, and in teaching methods. Or, as Mendelsohn (1994, p. 9) argues, "the real question of transfer may be, on one hand, the adequacy between the quality and content of the knowledge taught, and on the other, the constraints of the different domains where these skills are likely to be applied". The same author also states that what we call transfer may be a value judgment about the availability, degree of generality, or accessibility of acquired knowledge. These qualities allow us to control and adapt the acquired knowledge to different contexts and situation in a flexible way.

One way to promote the transfer of learning is to use the instructional design (ID), the practice of creating instructional experiences that make the acquisition of knowledge and skill more efficient, effective, and appealing. In fact, the ID is more than just procedures; it involves theory (instructional design theories). An ID theory offers explicit guidance on how to better help people to learn and develop (cf. Bruner, 1960, 1965, 1966; Carey, Barey, \& Dick, 2005; Dick, Carey, \& Carey, 2001; Gagné, 1970, 1974, 1985; Mayer, 2005). The major characteristics of an ID theory are: (1) design-oriented (focusing on means to attain given goals for learning or development), rather than description oriented (focusing on the results of given events), consequently, it is very useful to educators, because it provides direct guidance on how to achieve their goals; (2) identifies methods of instruction (ways to support and facilitate learning), and the situations in which those methods should and should not be used; (3) the methods of instruction can be broken into more detailed component methods, which provide more guidance to educators; and (4) the methods are probabilistic rather than deterministic, which means they increase the chances of attaining the goals rather than ensuring attainment of the goals (cf. Reiser, 2001a, 2001b; Willis, 2009; Wilson, Joanassen, \& Cole, 1993).

Therefore, we can say that ID is a creative pattern on rational, logical sequential process intended to solve problems. Another key element of our research is to train students for problem solving ability, using the principles of the Four Components Instructional Design Model (4C-ID), which will be described in more detail in the next section.

We chose the electric circuit theme because it is part of Physics syllabus and its acquisition process involves complex learning; that is, the integration of knowledge about contents related to electric circuits and the development of skills connected to problem solving abilities (on the electric circuits analysis).

Recent instructional theories tend to focus on authentic and whole learning tasks that require learners to address real-world problems as the driving force for transfer of learning (Merrill, 2002, 2007; van Merriënboer \& Kirschner, 2001). The main idea is that such tasks help learners to integrate the knowledge, skills, and attitudes necessary for effective task performance; give them the opportunity to learn to coordinate the constituent skills that make up complex task performance; and eventually enable them to transfer what is learned to their daily life or work settings (van Merriënboer \& de Croock, 1992).

Even though several instructional approaches and models that focus on whole learning tasks have been proposed, little empirical evidence exists with regard to the effects of the application of these whole-task approaches on the acquisition and transfer of complex cognitive skills.

The primary purpose of this study was to investigate how one particular whole-task approach (developed within the 4C-ID model by van Merriënboer in 1997, as compared to the use of a 
conventional instructional methodology), would affect learner acquisition and transfer of a complex task: to solve problems of basic electric circuits.

\section{Theoretical Framework - The 4C-ID Model}

\section{The Model Background}

The instructional design model that has major implications for the improvement of problem solving instructional design is the Four Component Instructional Design (4C-ID) theoretical model. This model, developed by van Merriënboer in the late 1990s, has proved to be effective for training and promoting better transfer performance with complex skills (van Merriënboer, 1997; van Merriënboer, Clark, \& de Croock, 2002; van Merriënboer, Jelsma, \& Paas, 1992; van Merriënboer \& Kirschner, 2007). The 4C-ID theoretical model takes into account current knowledge of human cognitive architecture, the limitations of Working Memory, and the three types of cognitive load (e.g. intrinsic, germane, and extraneous). According to the 4C-ID model, well designed environments for training complex skills consist of four interrelated components: (1) learning tasks, (2) supportive information, (3) procedural information, and (4) part-task practice. Each of these components is described below.

(1) Learning Tasks are the key component of the 4C-ID model. According to this model, in order to promote the construction of cognitive schemata and enable learners to achieve a desired learning goal, they should be provided with tasks that are concrete, authentic, and meaningful wholetask experiences. Ideally, these learning tasks should require learners to integrate and coordinate many constituent skills of a complex cognitive skill. By doing so, the model states that this will promote better understanding (i.e., schema construction) of the desired goal. The 4C-ID model recommends the learning tasks to be sequenced from the simplest to the most complex, and that learners receive more support on initial tasks. Commonly recommended types of support include worked examples, completion tasks where learners are presented with a problem and partial solutions to complete, and faded guidance where learners are initially provided with support (that is, gradually faded out as learner expertise increases) (van Merriënboer \& Kester, 2005).

(2) Supportive Information. This component provides information that describes how tasks should be organized and how problems should be approached. In other words, the purpose of supportive information is to help learners build connections between what they already know and information that would be helpful to successfully accomplish learning tasks. According to van Merriënboer, supportive information consists of three parts: Domain models (i.e. conceptual, structural, and causal models), which answer questions such as - "what is this?", - "how is this organized?", and - "how does it work?"; Systematic Approaches to Problem solving (SAPs), such as examples that show how an expert would perform and explain the processes of completing a task; and cognitive feedback, in which learners are asked to compare their solutions with those of experts. It has been found that in a first stage, supportive information is crucial because it enables learners to reach a goal or action not achievable without that support. However, as the learner achieves higher levels of competency, it is suggested that the support is gradually diminished until it is no longer needed. Research shows that it is critical to determine the right type and amount of support, and for it to fade at the appropriate time, because too much or too little support can hamper the learning process (van Merriënboer, Kirschner \& Kester, 2003).

(3) The third component of the 4C-ID model consists of the Procedural Information. This component provides information for recurrent constituent skills of learning tasks that are routine, usually presented in the form of step-by-step. According to this model, it is preferable that procedural information on domain-specific rules is presented in a just in time manner. That is, procedural information should be presented to learners precisely at the time when it is needed, and only pre- 
sented again if learners cannot recall it (van Merriënboer, 1997; van Merriënboer \& Kirschner, 2007). The 4C-ID model argues that, by presenting procedural information only when it is needed, temporal split attention effects can be prevented.

(4) The fourth component of the 4C-ID model is the Part-task Practice. This model recommends that part-task practice is provided for recurrent constituent skills for which automaticity is desired. This model states that part-task practice should begin only after the learner has practiced performing the whole task in order to ensure that the learner performs practice activities within a context that is meaningful to the learner (van Merriënboer, 1997; van Merriënboer \& Kirschner, 2007). Optimally, it is recommended that part-task practice is intermixed with learning tasks, instead of being presented in isolation. Previous research has indicated that the part-task strategy is effective in lowering the cognitive load of students, specifically for those with low prior knowledge. By contrast, students with higher prior knowledge learned significantly more by studying whole tasks than part-tasks (Ayres, 2006).

In summary, there are many reasons why the 4C-ID approach has been hypothesized and shown to promote better transfer performance on complex skills. By emphasizing whole-task practice, this model focuses on the integration and coordination of all constituent skills of a complex cognitive skill, while simultaneously promoting understanding (i.e., schema construction) of the complex skill. By doing so, this model emphasizes the ability to apply the complex cognitive skill in a wide variety of new real-life situations (van Merriënboer, 1997; van Merriënboer \& Kirschner, 2007). In addition, the 4C-ID approach has been shown to better promote transfer of learning due to task variability. High variability of whole-task practice enables learners to develop rich cognitive schemata, which allows for schema-based transfer of learning (cf. Paas \& van Merriënboer, 1994; Quilici \& Mayer 1996; Schilling, Vidal, Ployhart, \& Marangoni, 2003; van Merriënboer, Kester, \& Paas, 2006).

\section{Literature Review}

There are few research studies whose main goal has been to test the effectiveness of the 4C-ID model, particularly in domains taught in schools, because this model was first tested in certain domains of professional training.

Melo and Miranda (2014b) did a preliminary meta-analysis study on the effectiveness of the 4CID model on the knowledge acquiring and the transfer of learning, in school subjects. They found eight studies with the same research questions: what is the effectiveness of 4C-ID approach on learners' performance, on perceived cognitive load, and on instructional efficiency. Using Cohen's criteria for effect size magnitude, the overall mean effect size was moderate to large, $\mathrm{d}=$ 0.80 (95\% confidence interval 0.58-1.02).

In the early years of our century, there were some studies designed to test the effectiveness of the 4C-ID model in the professional training area. For example, Hoogved, Paas and Jochems (2001, 2003) studied the effectiveness of the 4C-ID model as an instructional system design approach to designing a teacher training program in the medical domain. In the first research, they compared two groups of teachers: one was trained to use the 4C-ID model to design instruction; and the other was trained to optimize its own design approach. After the training phase, the design quality of their educational products was measured by experts. It was found that teachers trained to use the 4C-ID model developed qualitatively better designs than the other teachers. The second study investigated whether teams or individuals benefited more from a 4C-ID approach to designing competence-based education. It was found that low achievers benefited more from the 4C-ID model when they were working in teams, but high achievers worked as well in teams as individually. 
In the law area, Nadolski, Kirschner, and van Merriënboer (2005) investigated the relation between the number of steps provided to learners and the quality of their learning of complex skills. It is hypothesized that students receiving an optimized number of steps will learn better than those receiving either the whole task in only one step, or those receiving it on a large number of steps. They varied the number of phases (one, four, or nine) of the whole task to determine the optimal balance between the advantages of whole-task practice and the disadvantages of cognitive overload caused by whole tasks that are too complex for learners. The results of this study showed that the participants exposed to an intermediate (i.e. four phases) number of steps outperformed (measured by the combination of practice-product quality and invested mental effort) all others on the compulsory learning task. No differences in performance of learning transfer task were found. A high number of steps proved to be less efficient for carrying out the learning task. The authors confirmed this conclusion with the results obtained in a follow-up study, conducted in 2006 (Nadolski, Kirschner \& van Merriënboer, 2006).

In the technical school domains, Sarfo and Elen $(2005,2006)$ developed a study whose main goal was to investigate the effectiveness (measured by the learning gain) of learning environments, developed with the specifications of the 4C-ID model (with and without ICT use) for the development of technical expertise in traditional Ghanaian classrooms. Three functionally equivalent classes of students from three similar technical secondary schools were randomly exposed to three different treatments. The sample consisted of 129 students. The experimental groups consisted of one control group with a regular method of teaching, and two experimental groups: a 4C-ID learning environment with ICT; and a 4C-ID learning environment without ICT. The content for the treatments was selected from the secondary technical education syllabus. Teachers were trained to implement the interventions. Results indicated that a 4C-ID learning environment promotes the development of technical expertise in secondary technical education better than with a conventional method. Moreover, results revealed no significant difference in learning gains for the $4 \mathrm{C}-\mathrm{ID}$, between the groups with and without ICT.

Kester, Kirschner, and van Merriënboer (2005) compared the effects of two information presentation formats on learning to solve problems in electrical circuits with the software Crocodile Physics ${ }^{\circledR}$. In one condition (the split-source format), information relating to procedural aspects of the functioning of an electrical circuit was not integrated in a circuit diagram; in the other, information in the integrated format condition was integrated in the circuit diagram. It was hypothesized that learners in the integrated format would achieve better test results than the learners in the split-source format. Equivalent-test problem and transfer-test problem performance were studied. Transfer test scores confirmed the hypothesis.

Lim, Reiser, and Olina (2009) compared the effects of the 4C/ID whole-task training and parttask training on the acquisition and transfer of a complex cognitive skill for novices and advanced learners. They found that both novices and advanced learners achieved better whole-task performance and better transfer performance if they received the 4C-ID whole-task training.

These results show that the 4C-ID model has the potential to promote the acquisition and transfer of knowledge, especially in the areas of vocational education and technical fields. It needs now to prove its effectiveness in teaching and learning in school subject matters in compulsory education. Our study was designed with this purpose.

\section{Research Questions and Hypotheses}

The primary purpose of our study was to investigate the effects of two instructional approaches, 4C-ID versus conventional, on acquisition and transfer of complex skills used to solve electrical circuits problems. This subject is part of the Physics syllabus for the $9^{\text {th }}$ grade compulsory education. In addition, we also researched the effects of these variables on learners' cognitive load and 
the instructional efficiency of this model. The specific research questions and the corresponding hypotheses are described below.

What are the comparative effects of the two approaches (4C-ID versus conventional) on: (a) knowledge acquisition in an electrical circuits context (learning reproduction); (b) learning transfer; (c) perceived cognitive load during the knowledge acquisition (reproduction) and transfer tests; and (d) instructional efficiency. The following hypotheses were formulated:

Hypothesis 1: Learners in the 4C-ID approach will perform better on a knowledge-acquisition test than learners in the conventional approach.

Hypothesis 2: Learners in the 4C-ID approach will perform better on a transfer test than learners in the conventional approach.

Hypothesis 3: Learners in the 4C-ID approach will show a lower perceived cognitive load during the knowledge-acquisition test than learners in the conventional approach.

Hypothesis 4: Learners in the 4C-ID approach will show a lower perceived cognitive load during the transfer test than learners in the conventional approach.

Hypothesis 5: The 4C-ID instructional approach will result in a higher level of instructional efficiency in the knowledge-acquisition test than the conventional approach.

Hypothesis 6: The 4C-ID instructional approach will result in a higher level of instructional efficiency in the transfer test than the conventional approach.

\section{Method}

\section{Participants}

A total of $1299^{\text {th }}$ grade students from a Lisbon private school (average age $=14.3$ years, $\mathrm{SD}=$ $0.54)$ participated in the study. The experimental group constituted three intact classes (78 students), and the control group constituted two intact classes (51 students). In the school, the 9th grade students were distributed in five classes in which Physics was taught by three teachers. To form the experimental and control groups we used the following criteria: Teacher A taught an experimental group, and teachers $\mathrm{B}$ and $\mathrm{C}$ taught an experimental group and a control group each. The learners participated in the study during their regularly scheduled classes. The three teachers received training about the essential learning objectives regarding the electrical circuits' topic.

\section{Independent Variable}

For both groups, the teaching of the theme "Electrical circuits" consisted of two 90 minute lessons. The choice of the theme of electrical circuitry has two main motivations: first, it is an issue that involves the integration of various skills such as interpreting, analysing and designing electrical circuits (complex skills); second, it is the first time in this education cycle that the theme is trained in Physics, so it does not require relevant prior knowledge to their learning. For this purpose, we constructed a digital environment developed with Adobe Flash ${ }^{\circledR}$ CS3 Professional.

A set of three class tasks (see Figure 1) was designed for the 4C-ID approach.

1) Learning class 1 focused on the concepts of electrical current and potential difference. Before starting the learning tasks, students had to observe a video (supportive information) with an explanation of the concepts of electric current direction and potential difference. After that, students had to follow a set of three learning tasks (T1, T2 and T3) corresponding to a solved example (T1), a partially solved exercise (T2), and a whole task to be solved without help (T3). 
2) Learning class 2 centered on the ability to design an electrical circuit schema. In this learning class, the supportive information focused on symbology used for the construction of electrical circuit diagrams. Then the students had to perform a sequence of six learning tasks (T1-T6) in which they had to identify symbols of electronic components. The first three tasks corresponded to solved and partially solved examples and exercises; the last three tasks had to be solved without help.

3) Learning class 3 focused on the concepts of serial and parallel association of lamps. In this learning class, the supportive information focused on the main features of an association in series and in parallel. Learning tasks are organized in worked examples (T1-T3), partially solved examples (T4-T6) and practical exercises (T7-T16).

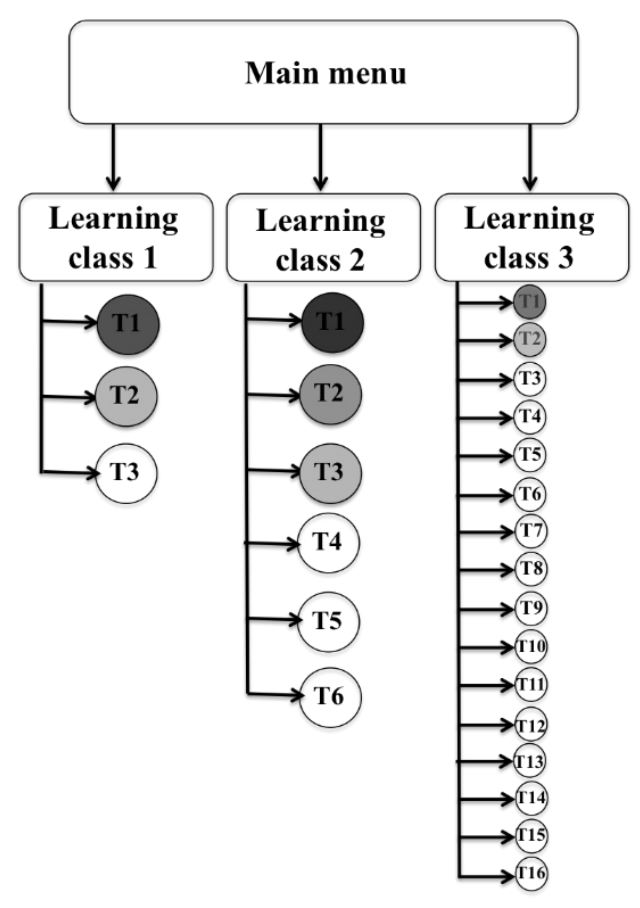

Figure 1: The structure of the learning environment (Melo \& Miranda, 2014a)

Figures 2 and 3 show a screen shot of two learning tasks of digital learning environment used by the experimental group. All pages have the same structure: supportive information button, a home page access button, and a bar indicating the tasks realized and unrealized. The different learning tasks were presented in the form of completion of items, true and false items (Figure 2), and drag and drop items (Figure 3).

The physical content covered in the digital learning environment has been submitted and validated by a panel of experts in the field of Physics teaching. The application part of the related graphic and multimedia design was also subjected and validated by a set of experts in the design and development of instructional materials with multimedia support.

In the conventional approach, the same contents were taught based on the traditional method; that is, teacher lecturing combined with exercises, similar to the 4C-ID application, but using pencils, paper, and calculators. At the beginning of each lesson, the teacher makes a presentation of the subject under study using the blackboard and/or the MSPowerPoint ${ }^{\circledR}$. After this, students have to solve a set of manual exercises on the theme of the lesson. During this resolution task, students can ask the teacher for cognitive and corrective feedback. 
Considere os circuitos A e B, em que as lâmpadas $L_{1}$ e $L_{2}$ têm as mesmas características e os geradores são iguais.
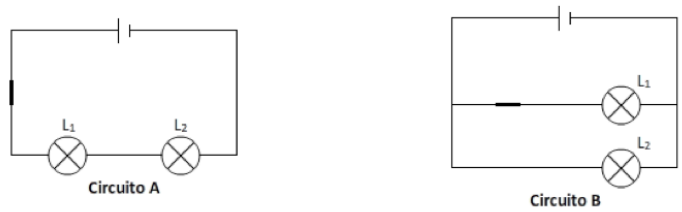

Classifique a afirmação seguinte como verdadeira ou falsa. Clique nos botões Verdadeira/Falsa.

A - Em ambos os circuitos as lâmpadas estão apagadas.

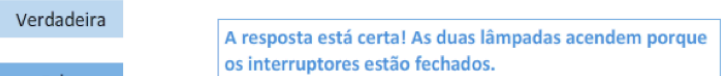
Falsa

$$
\text { os interruptores estão fechados. }
$$

Feedback (cognitive and corrective)

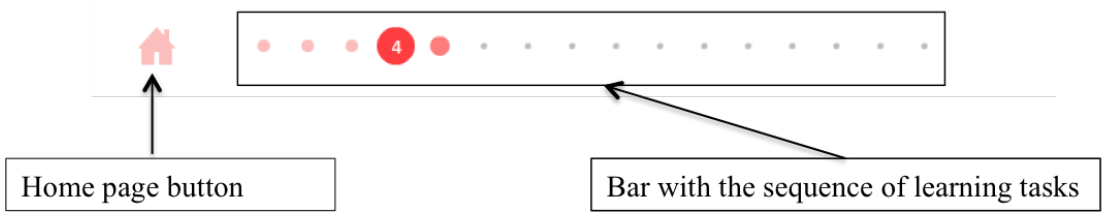

Figure 2: Screen shot of a true and false item in a learning task

Aula 3 , Tarefa 11

Considere os circuitos A, B, C e D, em que as lâmpadas têm as mesmas características.
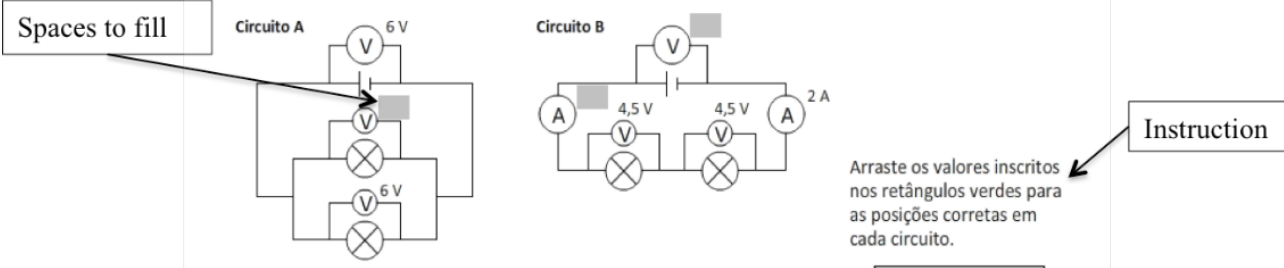

nos retângulos verdes para

as posições corretas em cada circuito.
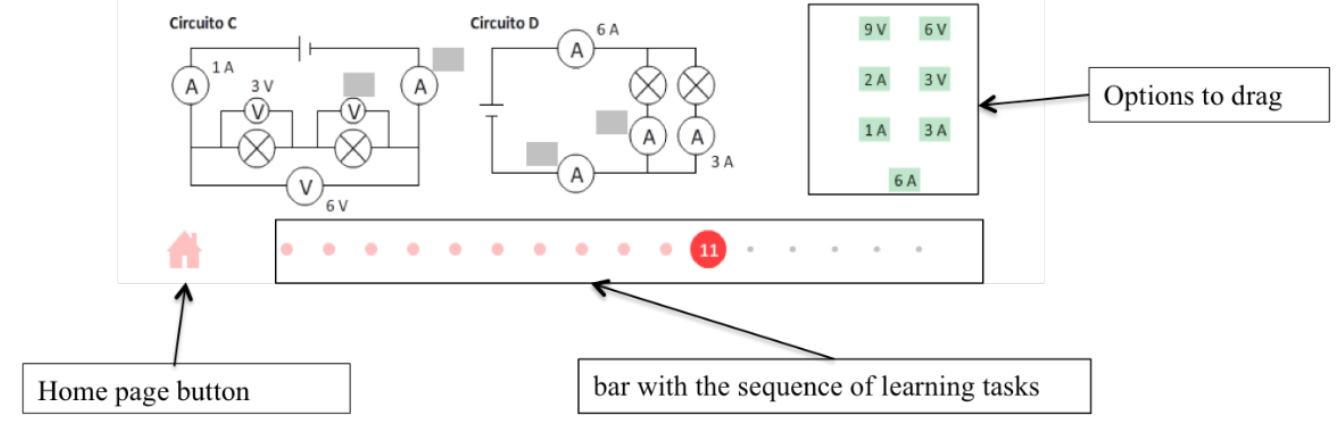

Figure 3: Screen shot of a drag and drop item in a learning task

The differences between the two approaches may be summarized as follows:

1) The way the instructional material was presented. In the traditional approach, during both lessons, the teacher demonstrated each of the part-task skills learners were expected to acquire. In contrast, in the 4C-ID approach, instead of demonstrating the part-task skills out of the context of the learning class, the teacher provided a model on how the students should 
solve the problem as a whole (to create a simple overview of how to analyse a circuit with multiple components).

2) Student practice activities. In the conventional approach, the practical activities required learners to focus on aspects related with part-task skills. As each skill was being demonstrated, students were given practical problems, which required them to evince each skill separately. In contrast, all practical activities in the 4C-ID approach required learners to analyse the principal properties of an electrical circuit with different components. During both lessons, the students had to study circuit schemas by following the demonstration (supportive information) and to solve a whole completion problem. Throughout these activities, supportive information was provided for the acquisition of non-recurrent skills, and procedural information was provided for the acquisition of recurrent skills.

\section{Dependent Variables}

\section{Knowledge acquisition}

The acquisition of knowledge on electrical circuits by the learners, after the instructional unit, was measured by an achievement test. This test required them to perform 14 items. All item responses were classified as right ( 1 point) or wrong ( 0 points). The classification obtained by each student could range between 0 and 14 points.

The reliabilities for the knowledge achievement test were calculated using the standardized Cronbach alpha and resulted in reliability indices of 0.96 and 0.97 for the first applications tests and for the follow-up, respectively. According to Peterson (1994), alpha should be 0.70 or higher for a set of items to be considered an adequate measure; so we can consider these instruments to be able to measure the values of learning acquisition.

\section{Learning transfer}

The ability to transfer the acquired knowledge was measured by a transfer test composed of a set of 14 items (with situations where the knowledge acquired about electrical circuits could be applied to new situations). As in the achievement test, items were classified as right (1 point) or wrong (points), so the test results ranged between 0 and 14 points. In Figure 4, we present an item of the transfer test that illustrates how the learning transferability was tested.

In the circuit of figure $3, \mathrm{R}$ is an electric resistance, and $\mathrm{L}_{1}$ and $\mathrm{L}_{2}$ are two identical lamps. In this circuit:

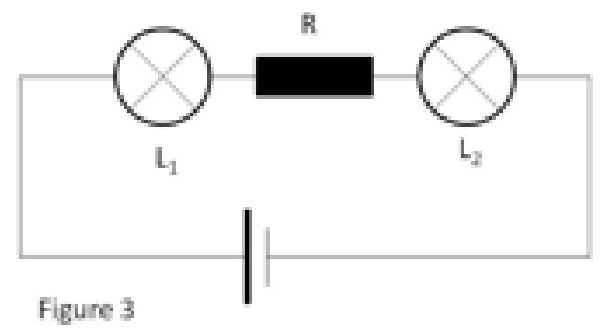

(A) $\mathrm{L}_{1}$ and $\mathrm{L}_{2}$ have the same brightness.

(B) $\mathrm{L}_{1}$ is brighter than $\mathrm{L}_{2}$.

(C) $\mathrm{L}_{2}$ is brighter than $\mathrm{L}_{1}$.

Figure 4: Transfer test item 
In this item, it is intended that students apply the knowledge acquired on characteristics of an association in series (electric current is constant at all points of the circuit) applied to a circuit with different receptors; in this case, bulb lamps and electric resistance. The student will have to consider that resistance is a receptor similar to the bulb lamp, because they convert electrical into internal energy and not only into light energy, so it does not affect the value of the electric current in any of the points of the circuit (which is one of the characteristics of this type of association).

The reliabilities for the transfer test were also calculated using the standardized Cronbach alpha and resulted in reliability indices of 0.95 for both the first application and the follow-up.

\section{Cognitive load}

Perceived cognitive load was measured by using a single student self-rating scale item developed by Paas and van Merriënboer (1993). The scale asked the participants to use a nine-point Likerttype scale to identify the amount of mental effort they invested to perform an assigned task. The cognitive load measures ranged from 1 (very, very low mental effort) to 9 (very, very high mental effort). The rating-scale was administered after the learner had completed each of the two achievement tests.

The reliabilities for the perceived cognitive load were calculated using the Cronbach alpha and resulted in reliability indices of 0.90 and 0.93 for the first applications tests and 0.97 and 0.96 for the follow-up application.

\section{Instructional efficiency}

The instructional efficiency values $(\mathrm{E})$ on each test were computed by the formula:

$$
E=\frac{P-M}{\sqrt{2}}
$$

(where $\mathrm{P}$ is Performance z-score and $\mathrm{M}$ is Cognitive Load z-score), and the $\mathrm{E}$ values are directly related to the performance score (e.g., knowledge acquisition test and transfer test).

Observing formula (1), it appears that if $\mathrm{P}$ and $\mathrm{M}$ scores are equal, the efficiency is null $(\mathrm{E}=0)$. If the $\mathrm{P}$ score is higher than the $\mathrm{M}$ score, the instructional efficiency is positive (higher performance in relation to less invested mental effort) and if the $\mathrm{P}$ score is lower than the $\mathrm{M}$ score, the instructional efficiency is negative (lower performance in relation to more invested mental effort).

\section{Experimental Procedure}

The research design used for this study was quasi-experimental in nature due to the assignment of intact groups to experimental conditions. Figure 5 shows an overview of the procedure for this study.

It is important to note that the lessons of the experimental group took place in a classroom in which each student had his/her computer with headphones. Students in this group were free to consult the supportive information and to read more than once the information generated by the cognitive and corrective feedback system. In each of these classes the teacher simply clarified technical issues related to the Adobe Flash ${ }^{\circledR}$ application Electrical Circuits. 


\section{Lesson 1: 90 min.}

\section{Introducing learning goals of the lesson;}

4C-ID Approach

2. Brief description of the learning environment;

3. Learning class $1-$ learning tasks $\mathrm{T} 1, \mathrm{~T} 2$ and $\mathrm{T} 3$;

4. Learning class 2 - learning tasks T1 to T6;

5. - Learning class 3 - learning tasks $\mathrm{T} 1$ to T8.
Conventional approach

2. Concepts lectured by the teacher;

3 . The teacher solves exercises from the students' manual.

$\downarrow \quad$ (2 days after)

Lesson 2: 90 min.

4C-ID Approach

1. - Learning class 3 - learning tasks T9 to T16.
Conventional approach

1. Reminding of the previous lesson;

2. Introducing the learning goals of the lesson;

3. Concepts lectured by the teacher;

4. The teacher solves exercises from the students manual.

$\downarrow \quad(10$ min break)

Knowledge-acquisition test (25 min)

Cognitive load assessment

Transfer test (25 min)

Cognitive load assessment

(follow-up - 10 days after)

Knowledge-acquisition test (25 min)

Cognitive load assessment

Transfer test (25 min)

Cognitive load assessment

Figure 5: An overview of the procedure

Results

\section{Achievement Tests (Knowledge Acquiring and Learning Transfer)}

As shown in Table 1, both groups performed fairly well on the knowledge acquisition test (mean scores were $87 \%$ and $81 \%$ for the experimental group, $87 \%$ and $77 \%$ for the control group). The experimental group $(80 \%$ and $82 \%$ ) had higher ratings in the learning transfer test compared with the control group (63\% and 64\%).

Table 1: Means and standard deviations of the achievement variables (knowledge acquiring and learning transfer)

\begin{tabular}{|c|c|c|c|c|}
\hline \multirow[t]{2}{*}{$\begin{array}{l}\text { Dependent } \\
\text { measures }\end{array}$} & \multicolumn{2}{|c|}{$\begin{array}{c}\text { Experimental group } \\
n=78 \\
M(S D) \\
\end{array}$} & \multicolumn{2}{|c|}{$\begin{array}{c}\text { Control group } \\
n=51 \\
M(S D) \\
\end{array}$} \\
\hline & 1st application & Follow-up & 1st application & Follow-up \\
\hline $\begin{array}{l}\text { Knowledge } \\
\text { acquisition test }\end{array}$ & $12.2(1.6)$ & $12.2(1.4)$ & $11.4(2.1)$ & $10.8(2.1)$ \\
\hline Transfer test ${ }^{\mathrm{a}}$ & $11.2(1.9)$ & $11.5(1.6)$ & $8.8(2.6)$ & $8.9(2.2)$ \\
\hline
\end{tabular}

${ }^{\mathrm{a}}$ maximum possible score was 14 points 
To examine differences between the two groups on the knowledge acquisition test and on the transfer test, we conducted the Kruskal-Wallis test as an alternative to one-way analysis of variance (ANOVA), because these two variables did not have a normal distribution and homogeneous variances as was proved by the Kolmogorov-Smirnov (KS) and Levene tests (see results in the appendix). The Kruskal-Wallis test revealed a significant overall main effect for the distribution results in the knowledge acquiring test for the experimental group $\left(\chi^{2}{ }_{K W}(1)=4.22, p=0.040, N\right.$ $=129$, for the first application and $\left(\chi_{K W}^{2}(1)=16.73, p=0.000, N=129\right)$. The effect size estimate was $\mathrm{d}=0.41$ (first application) and $\mathrm{d}=0.82$ (follow-up), indicating a moderately strong effect (Cohen, 1988).

With respect to the learning transfer test, the Kruskal-Wallis test showed a significant overall main effect for the distribution results in this test $\left(\chi_{K W}^{2}(1)=26.06, p=0.000, N=129\right.$, for the first application and the follow-up $\left(\chi_{K W}^{2}(1)=139.67, p=0.000, N=129\right)$. The effect size estimate was $\mathrm{d}=1.10$ (first application) and $\mathrm{d}=1.39$ (follow-up), indicating a strong effect.

\section{Perceived Cognitive Load}

Table 2 presents the mean values for the variable perceived cognitive load measured after the knowledge acquisition test and after the transfer test. Overall, we can see that, in terms of knowledge acquisition, the variability between the two groups is very low. However, with regard to the transfer of learning, we can observe that the difference between the two groups is stronger, (e.g. the students in the control group made a higher mental effort).

Table 2: Means and standard deviations of dependent variable perceived cognitive load for the achievement tests

\begin{tabular}{|c|c|c|c|c|}
\hline \multirow[t]{2}{*}{$\begin{array}{l}\text { Dependent } \\
\text { measures }\end{array}$} & \multicolumn{2}{|c|}{$\begin{array}{c}\text { Experimental group } \\
n=78 \\
M(S D)\end{array}$} & \multicolumn{2}{|c|}{$\begin{array}{c}\text { Control group } \\
n=51 \\
M(S D)\end{array}$} \\
\hline & 1st application & Follow-up & 1st application & Follow-up \\
\hline $\begin{array}{l}\text { Perceived cogni- } \\
\text { tive load }^{\text {a }} \\
\text { (knowledge } \\
\text { acquisition test) }\end{array}$ & $2.8(0.7)$ & $2.5(0.9)$ & $2.9(1.2)$ & $2.4(1.0)$ \\
\hline $\begin{array}{l}\text { Perceived cogni- } \\
\text { tive load } \text { (trans- }^{-} \\
\text {fer test) }\end{array}$ & $2.6(1.1)$ & $2.7(1.1)$ & $4.2(1.5)$ & $3.5(1.3)$ \\
\hline
\end{tabular}

${ }^{\mathrm{a}}$ nine point scale

Given that the variable perceived cognitive load respects the normal distribution and homogeneity principles (see appendix), we conducted the ANOVA one-way test-to examine the differences between the two groups.

The results of the one-way ANOVA test showed no significant differences in the perceived cognitive load measured after the knowledge acquisition test $\left(F(1,127)=0.766, p=0.383, \eta^{2}=0.006\right.$ for the first application test and $F(1,127)=0.967, p=0.327, \eta^{2}=0.008$ for the follow-up). With respect to the perceived cognitive load measure after the learning transfer test, the one-way ANOVA results showed that differences between the groups were statistically significant $\left(F(1,127)=44.337, p=0.000, \eta^{2}=0.259\right.$ for the first application test and $F(1,127)=12.298, p=$ $0.001, \eta^{2}=0.088$ for the follow-up). We also alculated the effect sizes for the perceived cognitive load variable measured after the knowledge acquisition $(0.16$ for the first application and 0.18 for 
the follow-up) and after the learning transfer test (1.20 for the first application and 0.38 for the follow-up).

\section{Instructional Efficiency}

Table 3 shows the results obtained on instructional efficiency in the knowledge acquisition and transfer tests, respectively by the experimental group and the control group. Figure 6 displays the distribution of this variable around line $\mathrm{E}=0$ for both groups in the first and follow-up applications. We can observe that the results obtained by the subjects in the experimental group correspond to greater efficiency (a better performance with less mental effort) in terms of reproduction of knowledge and learning transfer.

Table 3. Means and standard deviations of the instructional efficiency variable obtained in the achievement tests

\begin{tabular}{|c|c|c|c|c|}
\hline \multirow[t]{2}{*}{$\begin{array}{l}\text { Dependent } \\
\text { measures }\end{array}$} & \multicolumn{2}{|c|}{$\begin{array}{c}\text { Experimental group } \\
n=78 \\
M(S D)\end{array}$} & \multicolumn{2}{|c|}{$\begin{array}{c}\text { Control group } \\
n=51 \\
M(S D)\end{array}$} \\
\hline & 1st application & Follow-up & 1st application & Follow-up \\
\hline $\begin{array}{l}\text { Instructional } \\
\text { efficiency } \\
\text { (knowledge } \\
\text { acquisition test) }\end{array}$ & $+0.48(0.94)$ & $+0.48(0.82)$ & $+0.028(1.1)$ & - 0.57 (0.99) \\
\hline $\begin{array}{l}\text { Instructional } \\
\text { efficiency } \\
\text { (transfer test) }\end{array}$ & $+0.55(0.90)$ & $+0.42(0.80)$ & - $0.41(1.01)$ & $-0.25(0.76)$ \\
\hline
\end{tabular}

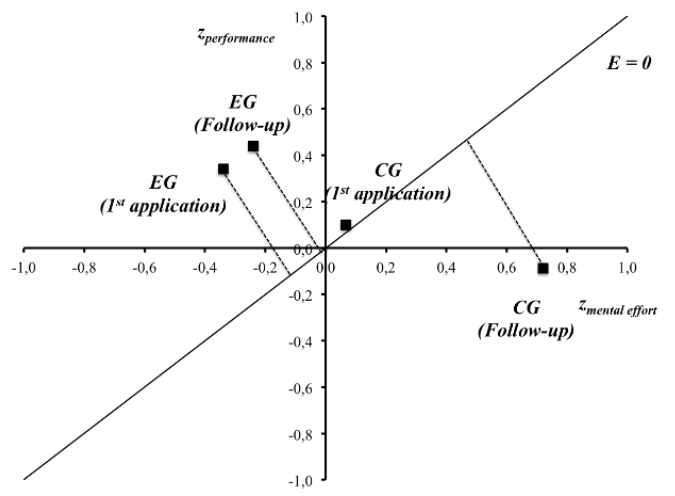

(a)

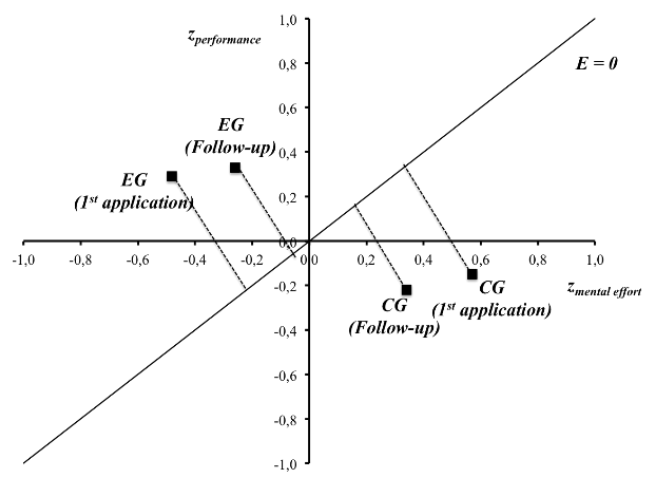

(b)

Figure 6: (a) Instructional efficiency obtained by the experimental group (EG) and the control group (CG) in the knowledge acquisition test; (b) Instructional efficiency obtained by the experimental group (EG) and the control group (CG) in the transfer test

(Melo \& Miranda, 2014b)

Since the instructional efficiency variable respects the normal distribution and homogeneity principles (see appendix), we conducted the ANOVA one-way test to examine the differences between the two groups.

One-way ANOVAs revealed a significant statistical difference between the experimental and the control group in the results for instructional efficiency obtained with the knowledge acquisition 
test $\left(F(1,127)=6.350, p=0.013, \eta^{2}=0.048\right.$ for the first application test and $F(1,127)=43.028, p$ $=0.000, \eta^{2}=0.253$ for the follow-up) and with the learning transfer test $(F(1,127)=32.800, p=$ $0.000, \eta^{2}=0.205$ for the first application test and $F(1,127)=21.742, p=0.000, \eta^{2}=0.146$ for the follow-up). The estimate for the effect sizes was 0.45 and 1.18 for instructional efficiency measured after the knowledge acquisition test, and 1.03 and 0.84 for instructional efficiency measured after the learning transfer test.

\section{Discussion}

The purpose of this research was to study the effects of two instructional approaches (the 4C-ID versus the conventional) in terms of knowledge acquisition and learning transfer of complex skills in the domain of electrical circuits problem solving, integrated in the Physics syllabus of the Portuguese compulsory educational system. Our objective was also to study the cognitive load variables perceived by the students when solving the achievement tests and the instructional efficiency of the 4C-ID model when compared with the conventional method of instruction. To discuss the results obtained, we will interpret the hypotheses formulated previously so that they seem more plausible in the light of the literature review.

\section{The Effects of the Instructional Approach on Knowledge Acquiring and Learning Transfer}

The first two hypotheses are related to the acquisition and transfer of learning on electrical circuits. The results of the experiment support the hypothesis that a 4C-ID learning environment contributes to the development of skills related to the electrical circuits problem solving. This result indicates that, when compared with the control group, the experimental group was better able to solve problems on electrical circuits. Many authors (De Corte, 2003; Merril, 2002; van Merriënboer \& Paas, 2003; van Merriënboer, Schuurman, de Croock, \& Paas, 2002) have found that a 4C-ID learning environment promotes the acquisition of coordinated and integrated sets of knowledge and skills (i.e. it facilitates complex learning).

The results of the statistical test applied to the knowledge acquisition and learning transfer variables showed a better performance of the experimental group in comparison with the control group. The results indicate a greater effect over the independent variable in the ability to transfer knowledge. We believe that these outcomes can be explained by the fact that the 4C-ID learning environment developed by us appealed to a large contextual variability of the learning tasks than the conventional environment. Salomon and Perkins (1989), Shapiro and Schmidt (1982), and Singley and Anderson (1989), among others, have pointed to the benefits of tasks variability on learning transfer.

Another possible cause for a superior transfer performance may be related to the emphasis given by the 4C-ID approach to promoting schema construction for generalized knowledge, which can be used for problem solving in different situations. For instance, in the subtopic series and parallel lamps circuits, the students were able to transfer the generalized knowledge about the characteristics of these two types of circuits to the analysis of new circuits involving different devices such as resistors. Thus, students were able to transfer the effects of a lamp in the circuit equivalent to a resistance, since they are only receptors that offer resistance to electrical current movement. The results of the two items on the transfer test (one related to series circuits and the other related to parallel circuits) indicate that the experimental group performed significantly better on these two items $(\mathrm{M}=0.74, \mathrm{SD}=0.44$ for the series circuit item, and $\mathrm{M}=0.78, \mathrm{SD}=0.42$ for the parallel circuit item) than the control group $(\mathrm{M}=0.55, \mathrm{SD}=0.50$ for the series circuit item, and $\mathrm{M}=0.61, \mathrm{SD}=0.49$ for the parallel circuit item). The results of the non-parametric test revealed that the distribution of two the items was not the same in both the experimental and the control 
group (Mann-Whitney $U, p=0.022$ for series circuit, and $p=0.033$ for parallel circuit). Perhaps the reason why the 4C-ID group was able to do a better transfer of learning than the conventional group is related to the way they generally acquired knowledge on the topic studied they did it in a more systematic way than the control group. This generalized knowledge in the context of the 4C-ID model is the supportive information presented before practice (class tasks) and it was made accessible to learners throughout the instruction process via multimedia messages. We believe they had the opportunity to associate new information to what they already knew, which promoted a better understanding of the content while experiencing a low perceived cognitive load. In the control group (conventional approach) the information describing the characteristics of each type of circuits was presented when the teacher gave students practical examples.

Another aspect of the supportive information focuses on the fact that this describes the SAPs that specify the successive phases of the process of problem solving and some basic rules that can be useful to successfully run each of those stages. In the experimental group this type of information was always available when the students must perform the learning tasks. Figure 7 shows a supportive information screen shot with respect to the characteristics of series and parallel circuits. This information is given in multimedia format in which an expert explains and clarifies the characteristics of this type of association lamps.
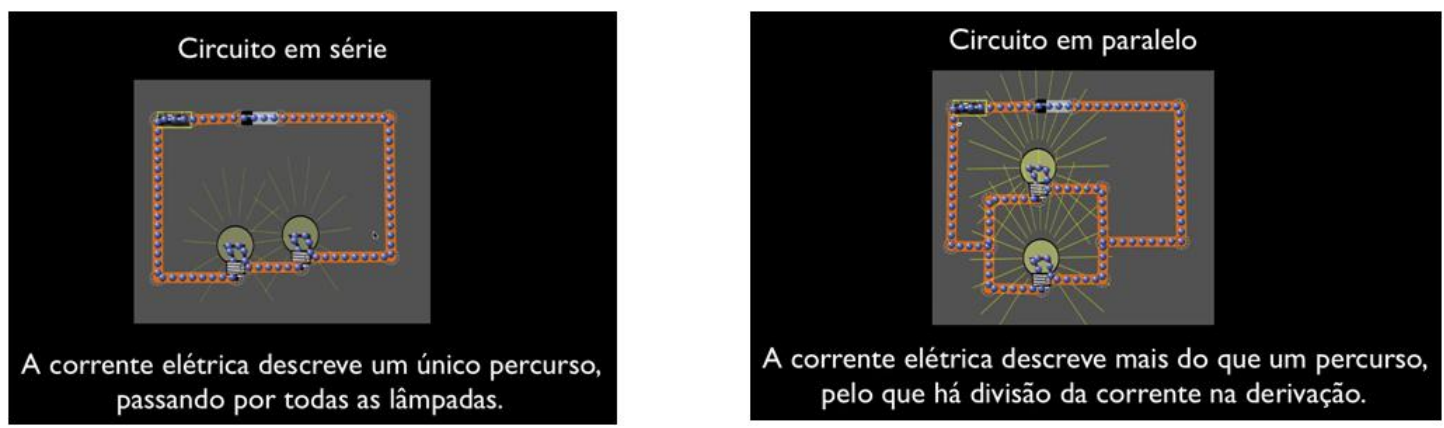

Figure 7: Screen shot of supportive information about series and parallel circuits

Cognitive feedback is another key aspect of supportive information as it is given in terms of quality of performance in carrying out learning tasks. In this perspective it is considered that there is no purely correct or incorrect behavior with regard to problem solving and reasoning behind this process of resolution. This type of feedback leads many students to make a critical comparison of the solutions to the presented solution, producing a deeper understanding of the studied subject (cf. Hattie, 2009; Hattie \& Yates, 2014). Figure 8 shows a cognitive feedback on a worked example about the relationship between voltages on the lamps connected in series. In this example, students had to press the button "Resposta" (answer) and the feedback system classified the answer as true or false and shows an explanation. It is important to note that students cannot advance to the next task without reading the information generated by the feedback system.

To sum up, the findings on learners' performance suggest that the 4C-ID approach was more effective than the conventional approach in terms of learner performance when acquiring knowledge and transferring learning on electric circuits' basic analysis. This means that the 4CID approach helped learners to acquire general knowledge and to apply this knowledge to new situations.

We believe that these differences in the two approaches are linked to the 4C-ID model characteristics, in particular in that there is a systematic approach to solve problems of electrical circuits and the cognitive feedback system, which contributes to a decrease in the cognitive load associated with instruction, as we will see in the next section. 
Another factor that may be contributing to a better performance of the experimental group is linked to the fact that this group work methodology appeals to more autonomous work, since learners will spend more time in self-study, which did not occur with the control group in which the teaching strategy was more centered on the teacher.

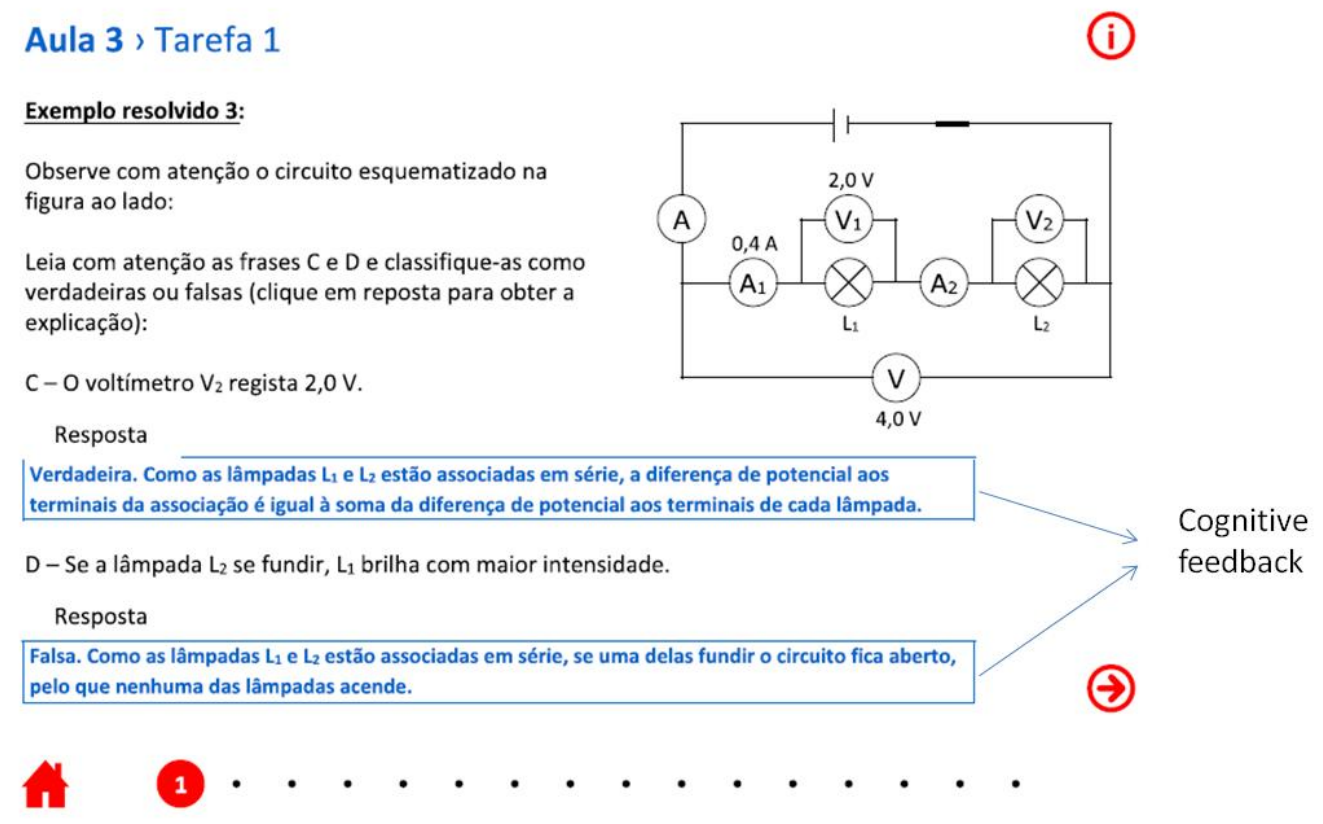

Figure 8: Screen shot of cognitive feedback about voltage in series circuits

\section{The Effect of the Instructional Approach on Perceived Cognitive Load}

The perceived cognitive load measured after the knowledge acquisition test, showed no differences between the two groups (hypothesis 3 ). The perceived cognitive load assessed after the learning transfer test revealed that the experimental group perceived a significantly lower mental effort than the control group (hypothesis 4). So, we can conclude that learners being taught through 4C-ID approach were able to perform better without experiencing a greater cognitive load. On the contrary, they perceived a lower cognitive load than the control group. This result may be explained by the fact that the 4C-ID model includes an effective management of cognitive load associated with learning tasks. This was done in three ways. First, in order to decrease the cognitive load inherent to the learning material (intrinsic cognitive load), a simple to complex task sequencing was used (e.g. first presenting a simple electrical circuit, then a more complex circuit schema). Second, extraneous load (caused by the instructional feature of learning material) was minimized by presenting a structured sequence of learning tasks. That is, instead of presenting students with a series of conventional problems about electrical circuits, which usually cause a high extraneous cognitive load, a series of examples was provided, each followed by a completion problem. Third, in order to increase germane cognitive load, (load relevant for learning or schema construction) learning tasks within the same class task were presented in various contexts. Thus, with this meticulous management of all three types of cognitive load we could obtain a performance improvement without increasing the perceived cognitive load in the 4C-ID approach.

In addition, to facilitate the construction of cognitive schemas, supportive information (the second component of 4C-ID model) explains how a domain is organized and how to approach problems 
in this domain so that learners can fruitfully work on non-recurrent aspects of learning tasks within the same class task. This supportive information was provided before each class task and was made accessible to learners throughout task practice via multimedia messages. The reason for presenting supportive information previous to practice was that the information describing a mental model (e.g. how an electric circuit is organized, what is the function of each component in the circuit) and cognitive strategies (e.g. rules to do an efficient analysis of a circuit) usually has a high inherent complexity. A particularly important type of supportive information for learners is feedback on the quality of their performance. This so-called cognitive feedback refers only to the non-recurrent aspects of performance. This information included prompts, cues and questions that help learners to construct or reconstruct their cognitive schemas in such a way that future performance is improved (McKendree, 1990). Cognitive feedback stimulates learners to reflect on the quality of both their personal problem-solving processes and the solutions they have found, so that more effective cognitive strategies and mental models can be developed. One factor that has been particularly taken into consideration in the learning environment design with 4C-ID model was cognitive feedback, since in all learning tasks there is always information about the solutions found by the students.

To facilitate rule automation, procedural information (presented during task practice - just-intime information) specifies exactly how to perform the recurrent aspects of learning tasks and part-task practice provide additional repetition for these recurrent aspects that need to be developed up a very high level of automaticity (e.g. how to use voltmeter and ammeter). Another characteristic of the procedural information is the corrective feedback given on the recurrent aspects of performance. In contrast to cognitive feedback, the main function of corrective feedback is to detect and correct errors. So the learner can carry on his or her present work in a more efficient, effective and correct manner. In the 4C-ID approach the corrective feedback system informs learners that there was an error and why there was an error, but without simply stating the correct action (e.g. on drag-and-drop task learners had to drag values of current intensity or tension to the right position in a circuit; if he or she made the wrong choice, a message as "Please notice the relative positions of the components on the circuit" would appear).

\section{The Effect of the Instructional Approach on Instructional Efficiency}

As predicted, learners in the 4C-ID approach showed a significantly higher level of instructional efficiency on both achievement tests. These findings suggest that the 4C-ID approach was not only efficient for knowledge acquisition of electrical circuits, but also for the learning transfer. Both were computed by combining the results of the achievement test and the perceived cognitive load using formula (1). Melo and Miranda (2014b) did a graphical analysis (Figure 6) of the dissimilarities in the two groups regarding the differences in terms of instructional efficiency. They found that, learners in the experimental group showed a higher level of instructional efficiency on the knowledge acquisition test and on the learning transfer test.

\section{Future Research}

The findings of this study suggest some direction for future research. The first issue concerns the measurement of the perceived cognitive load. This variable was measured by a single rating scale that assessed the amount of mental efforts learners invested on the task they received. This way of assessing cognitive load does not discriminate the three types of cognitive load inherent to the instructional material. For example, two students may indicate the same mental effort and yet we do not know if this measure was a result of the contribution of only a specific type of cognitive load (i.e., intrinsic, extraneous or germane cognitive load). Second, future studies should include a collection of qualitative data in order to answer questions such as: how did treatment affect the 
learners' learning process? This way of analysis could give us information about the type of mental schemas that will improve better the transfer of learning. Gathering data of this nature would help us to provide a clearer spectrum of how the 4C-ID approach affects learning strategies and to what extent the various components of the model were more beneficial to the learning process.

Finally, we think it will be interesting to study the effect of some variables in connection with the way students face learning tasks. For example, no doubt it would be fascinating to analyse the relations between the students' approaches to learning (SAL) (e.g., Biggs, 1985; Marton \& Säljö, 1976, among others) and the results in achievement tests and the perceived cognitive load.

\section{Conclusion}

The findings of this study have one main practical implication in the field of instructional system design: the use of a learning environment designed using the principals of the 4C-ID model was more effective and efficient with regard to knowledge acquisition and learning transfer than a traditional or conventional instructional method.

Our research results add a new contribution to the effectiveness of the 4C-ID model in helping students learn complex skills in the context of their curricular contents. In other words, it increases the generalizability of the 4C-ID model.

\section{References}

Anderson, J. (1983). The architecture of cognition. Cambridge, MA: Harvard University Press.

Ayres, P. (2006). Impact of reducing intrinsic cognitive load on learning in a mathematical domain. Applied Cognitive Psychology, 20(3), 287-298.

Bassok, M. (1990). Transfer of domain-specific problem-solving procedures. Journal of Experimental Psychology: Learning, Memory and Cognition, 15(1), 153-166.

Biggs, J. (1985). The role of meta-learning in study processes. British Journal of Educational Psychology, $55,185-212$.

Bransford, J., Brown, A., \& Cocking, R. (Eds.) (2000). Learning and transfer. In How people learn: Brain, mind, experience and school (pp. 51-78). Washington DC: National Academy Press.

Brown, A. (1978). Knowing when, where, and how to remember: A problem of metacognition. In R. Glasser (Ed.), Advances in instructional psychology (Vol. 1, pp. 77-165). Hillsdale, NJ: Erlbaum.

Brown, A. (1987). Metacognition, executive control, self-regulation, and other more mysterious mechanisms. In F. E. Weinert \& R. Kluwe (Eds.). Metacognition, motivation, and understanding (pp. 1-16). Hillsdale, NJ: Erlbaum.

Brown, A., \& Campione, J. (1981). Learning to learn. On training students to learn from texts. Educational Research, 10(2), 14-21.

Brown, A., \& Campione, J. (1986). Training for transfer: Guidelines for promoting flexible use of trained skills. Advances in Psychology, 31, 257-271.

Bruner, J. (1960). The process of education. USA: Harvard University Press.

Bruner, J. (1965). The growth of the mind. American Psychologist, 20(12), 1007-1017.

Bruner, J. (1966). Toward a theory of instruction. USA: Belknap Pres.

Carey, J., Barey, L., \& Dick, W. (2005). The systematic design of instruction. Boston, MA: Allyn \& Bacon.

Chi, M., Glaser, R., \& Rees. E. (1982). Expertise in problem solving. In J. R Sternberg (Ed.). Advances in the psychology of human intelligence (Vol. 1, pp. 7-76). Hillsdale, NJ: Erlbaum. 
Cohen, J. (1988). Statistical power analysis for the behavioral sciences ( ${ }^{\text {nd }}$ ed.). NJ: Lawrence Erlbaum Associates.

De Corte, E. (2003). Designing learning environments that foster the productive use of acquired knowledge and skills. In E. De Corte, L. Verschaffel, N. Entwistle, \& J. J. G. van Merriënboer (Eds.). Powerful learning environments: Unravelling basic components and dimensions (pp.21-35). Oxford, UK: Elsevier Science.

Dewey, J. (1916). Democracy and education. An introduction to the philosophy of education. The MacMillan Company. Retrieved from http://en.wikisource.org/wiki/Democracy_and_Education

Dick, W., Carey, L., \& Carey, J. (2001). The systematic design of instruction (5 ${ }^{\text {th }}$ ed.). USA: Allyn and Bacon.

Gagné, R. (1970). The conditions of learning ( $2^{\text {nd }}$ ed.). New York: Holt, Rinehart and Winston, Inc.

Gagné, R. (1974). Essentials of learning for instruction (2 ${ }^{\text {nd }}$ ed.). Hinsdale, IL: The Dryden Press.

Gagné, R. M. (1985). The conditions of learning and theory of instruction. New York: Holt, Rinehart and Winston.

Gick, M., \& Holyoak, K. (1983). Schema induction and analogical transfer. Cognitive Psychology, 15, 138.

Greeno, J. (1997). On claims that answer the wrong questions. Educational Researcher, 26(2), 5-17.

Greeno, J., Collins, A., \& Resnick, L. (1996). Cognition and learning. In D. Berliner, \& R. Calfee (Eds.). Handbook of educational psychology (pp.15-46). New York: Macmillan.

Hattie, J. (2009). Visible learning. A synthesis of over 800 meta-analyses related to achievement. New York: Routledge.

Hattie, J., \& Yates, G. (2014). Visible learning and the science of how we learning. New York: Routledge.

Hoogveld, A., Paas, F. \& Jochems, W. (2001). The effects of a web-based training in an instructional systems design approach on teachers' instructional design behavior. Computer in Human Behavior, 17, 363-371. DOI: 10.1016/S0747-5632(01)00013-9.

Hoogveld, A., Paas, F., \& Jochems, W. (2003). Application of an instructional systems design approach by teachers in higher education: individual versus team design. Teaching and Teacher Education, 19, 581-590. DOI: 10.1016/S0742-051X(03)00055-6.

Kester, L., Kirschner, P., \& van Merriënboer, J. (2005). The management of cognitive load during complex cognitive skill acquisition by means of computer-simulated problem solving. British Journal of Education Psychology, 75, 71-85.

Kintsch, W. (1977). Memory and cognition. New York: Wiley.

Lave, J., \& Wenger, E. (1995). Situated learning: Legitimate peripheral participation (4 ${ }^{\text {th }}$ ed.). New York: Cambridge University Press.

Lim, J., Reiser, R. A., \& Olina, Z. (2009). The effects of part-task and whole-task approaches on acquisition and transfer of a complex cognitive skill. Education Technology Research Development, 57, 6177. DOI: $10.1007 / \mathrm{s} 11423-007-9085-\mathrm{y}$.

Marton, F., \& Säljö, R. (1976). On qualitative differences in learning. I - Outcome and process. British Journal of Educational Psychology, 46, 4-11.

Mayer, R. E. (2005). Cognitive theory of multimedia learning. In R. E. Mayer (Ed.). The Cambridge handbook of multimedia learning (pp. 31-48). USA: Cambridge University Press.

McKendre, J. (1990). Effective feedback content for tutoring complex skills. Journal of Human-Computer Interaction, 5(4), 381-413.

Melo, M., \& Miranda, G. L. (2014a, June). Applying the 4C-ID Model to the design of a digital educational resource for teaching electric circuits: Effects on student achievement. Proceedings of the 2014 Work- 
shop on Interaction Design in Educational Environments (IDEE '14), Spain, Albacete, 8-14. DOI=10.1145/2643604.2643605.

Melo, M., \& Miranda, L, G. (2014b, in press). The effects of 4C-ID model approach on acquisition and transfer of knowledge about electric circuits. In S. Barbosa, P. Chen, X. Du, J. Filipe, O. Kara, I. Kotenko, K.M. Sivalingan \& T. Washio (Eds.). IDEE-2014 in Communications in Computer and Information Science (CCIS), Heidelberg: Springer.

Mendelsohn, P. (1994, September 29). Le transfert de connaissances: la pierre philosophale de l'enseignant. Conférence introductive au Colloque sur les "Transferts de connaissances". Lyon, France.

Merrill, D. (2002). First principles of instruction. Educational Technology, Research and Development, $50(3), 43-59$.

Merrill, D. (2007). First principles of instruction: A synthesis. In R. Reiser \& J. Dempsy (Eds). Trends and issues in instructional design and technology ( $2^{\text {nd }}$ ed.), (pp. 341-346). NJ: Pearson.

Nadolski, R., Kirschner, P., \& van Merriënboer, J. (2005). Optimizing the number of steps in learning tasks for complex skills. British Journal of Education Psychology, 75, 223-237.

DOI: $10.1348 / 000709904 X 22403$

Nadolski, R., Kirschner, P., \& van Merriënboer, J. (2006). Process support in learning tasks for acquiring complex cognitive skills in the domain of law. Learning and Instruction, 16, 266-278.

DOI:10.1016/j.learninstruc.2006.03.004

Paas, F., \& van Merriënboer, J. (1993). The efficiency of instructional conditions: An approach to combine mental-effort and performance measures. Human Factors, 35, 737-743.

Paas, F., \& van Merriënboer, J. (1994). Instructional control of cognitive load in the training of complex cognitive tasks. Educational Psychology Review, 6, 51-71. DOI: 10.1007/BF02213420.

Packer, M. (2001). The problem of transfer, and sociocultural critique of schooling. Journal of the Learning Sciences, 10(4), 493-515.

Pavlov, I. (2003/1927). Conditioned reflexes (2nd ed.). New York: Dover Publications

Perkins, D., \& Salomon, G. (1992). Transfer of learning. In International Encyclopedia of Education (2 ${ }^{\text {nd }}$ ed.). Oxford, England: Pergamon Press. Retrieved from https://learnweb.harvard.edu/alps/thinking/docs/traencyn.htm

Peterson, R.A. (1994). A meta-analysis of Cronbach's coefficient alpha. Journal of Consumer Research, 21(2), 381-391.

Quilici, J., \& Mayer, R. (1996). Role of examples in how students learn to categorize statistics word problems. Journal of Educational Psychology, 88(1), 144-161.

Reiser, R. (2001a). A history of instructional design and technology. Part I: A history of instructional media. Educational Technology Research and Development, 49(1), 53-64.

Reiser, R. (2001b). A history of instructional design and technology. Part I: A history of instructional design. Educational Technology Research and Development, 49(2), 57-67.

Resnick, L., \& Collins, A. (1996). Cognition and learning. In E. De Corte \& F. E. Weinert (Eds.). International encyclopedia of developmental and instructional psychology (pp. 377-381). UK: Pergamon Press.

Rogoff, B., \& Chavajay, P. (1995). What's become of research on the cultural basis of cognitive development? American Psychologist, 50, 859-877.

Salomon, G., \& Perkins, D. (1989). Rocky roads to transfer: Rethinking mechanisms of neglected phenomenon. Educational Psychologist, 24(2), 113-142.

Sarfo, F., \& Elen. J. (2005, July). Powerful learning environments and the development of technical expertise in Ghana: investigating the moderating effect of instructional conceptions. Proceedings of the 5th 
IEEE International Conference on Advanced Learning Technologies (ICALT'2005), Kaohsiung, Taiwan.

Sarfo, F., \& Elen, J. (2006). The design of effective support for the acquisition of technical expertise. In G. Clarebout \& J. Elen. Avoiding simplicity, confronting complexity (pp. 417-422). Rotterdam: Sense Publishers.

Schilling, M., Vidal, P., Ployhart, R., \& Marangoni, A. (2003). Learning by doing something else: Variation, relatedness, and the learning curve. Management Science, 49, 39-56.

Shapiro, D., \& Schmidt. R. (1982). The schema theory: Recent evidence and developmental implications. In J. A. S. Kelso and J. E. Clark (Eds). The development of movement control and coordination (pp. 113-150). New York: John Wiley.

Simon, H. (1982). Cognitive processes of experts and novices. In J.-J. Ducret, C. Monnier, O. Rod, \& A. Wells (Eds.). Cahiers de la Fondation Archives Jean Piaget $N^{o}$. 2-3 (pp. 155-182). Genève: Foundation des Archives Jean Piaget.

Singley, M., \& Anderson, J. (1989). The transfer of cognitive skill. Cambridge, MA: Harvard University Press.

Skinner, B. (1965/1953). Science and human behavior. New York: The Free Press.

Smith, L. (1993). The concept of same. In W. Reese (Ed.), Advances in child development behavior (pp. 215-317). USA: Academic Press.

Sweller, J., Ayres, P., \& Kalyuga, S. (2011). Cognitive load theory. New York: Springer.

Thorndike, E., \& Woodworth, R. (1901). The influence of improvement in one mental function upon the efficiency of other functions, Psychological Review, 8, 247-261, 384-395, 553-564.

DOI:10.1037/h0074898; DOI:10.1037/h0071280; DOI:10.1037/h0071363.

van Merriënboer, J. (1997). Training complex cognitive skills. Englewood Cliffs, NJ: Educational Technology Publications.

van Merriënboer, J., Clark, R., \& de Croock, M. (2002). Blueprints for complex learning: The 4C/ID model. Educational Technology, Research and Development, 50(2), 39-64.

van Merriënboer J., \& de Croock, M. (1992). Strategies for computer-based programming instruction: Program completion versus program generation. Journal of Educational Computing Research, 8, 365394.

van Merriënboer, J., Jelsma, O., \& Paas, F. (1992). Training for reflective expertise: A four-component instructional design model for training complex cognitive skills. Educational Technology, Research and Development, 40(2), 23-43.

van Merriënboer, J., \& Kester., L. (2005). The four-component instructional design model. Multimedia principles in environments for complex learning. In R. Mayer (Ed.). The Cambridge handbook of multimedia learning (pp.71-95). New York: Cambridge University Press.

van Merriënboer, J., Kester, L., \& Paas, F. (2006). Teaching complex rather than simple tasks: Balancing intrinsic and germane load to enhance transfer of learning. Applied Cognitive Psychology, 20, 343352. DOI: $10.1002 /$ acp. 1250.

van Merriënboer, J., \& Kirschner, P. (2001). Three worlds of instructional design: State of the art and future directions. Instructional Science, 29, 429-441.

van Merriënboer, J., \& Kirschner. P. (2007). Ten steps to complex learning: A systematic approach to Four-Component Instructional Design. NJ: Lawrence Erlbaum Associates.

van Merriënboer, J., Kirschner, P., \& Kester, L. (2003). Taking the load off a learner's mind: Instructional design for complex learning. Educational Psychologist, 38, 5- 13. DOI: 10.1207/S15326985EP3801_2

van Merriënboer, J., \& Paas, F. (2003). Powerful learning and the many faces of instructional design: Towards a framework for the design of powerful environments. In E. De Corte, L. Verschaffel, N. 
Entwistle, \& J. J. G. van Merriënboer (Eds). Powerful learning environments: Unravelling basic components and dimensions (pp. 21-35). Oxford, UK: Elsevier Science.

van Merriënboer, J., Schuurman, J., Marcel de Croock, J. G., \& Paas, F. (2002). Redirecting learners' attention during instruction: Effect on cognitive load, transfer test performance and training efficiency.

Learning and Instruction, 12, 11-37.

Vosniadou, S., \& Ortony, A. (1989). Similarity and analogical reasoning. Cambridge: Cambridge University Press.

Vygotky, L. (1978). Mind in society. The development of higher psychological processes. USA: The President and Fellows of Harvard College.

Willis, J. (2009). Pedagogical ID versus process ID: Two perspectives in contemporary instructional design theory. International Journal of Technology in Teaching and learning, 5(2), 93-105.

Wilson, B. G., Jonassen, D. H., \& Cole, P. (1993). Cognitive approaches to instructional design. In G. M. Piskurich (Ed.). The ASTD handbook of instructional technology (pp. 21.1-21.22). New York:

McGraw-Hill. 


\section{Appendix: Normality and variance homogeneity test for studied variables}

\begin{tabular}{|c|c|c|c|c|c|c|}
\hline \multirow{2}{*}{\multicolumn{3}{|c|}{ Variable }} & \multicolumn{2}{|c|}{ Kolmogorov-Smirnov } & \multicolumn{2}{|c|}{$\begin{array}{c}\text { Variance } \\
\text { homogeneity }\end{array}$} \\
\hline & & & Statistic & p-value & Levene & $\begin{array}{c}\mathrm{p}- \\
\mathrm{value}\end{array}$ \\
\hline \multirow{4}{*}{ 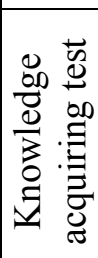 } & 1st application & $\mathrm{EG}$ & 0.221 & 0.000 & \multirow{2}{*}{5.79} & \multirow{2}{*}{0.018} \\
\hline & 1st application & $\mathrm{CG}$ & 0.177 & 0.000 & & \\
\hline & Follow-up & EG & 0.220 & 0.000 & \multirow{2}{*}{14.45} & \multirow{2}{*}{0.000} \\
\hline & Follow-up & $\mathrm{CG}$ & 0.165 & 0.001 & & \\
\hline \multirow{4}{*}{ 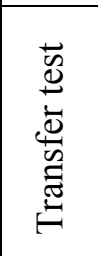 } & 1st application & EG & 0.182 & 0.000 & \multirow{2}{*}{6.96} & \multirow{2}{*}{0.009} \\
\hline & 1st application & $\mathrm{CG}$ & 0.140 & 0.014 & & \\
\hline & Follow-up & EG & 0.176 & 0.001 & \multirow{2}{*}{8.62} & \multirow{2}{*}{0.004} \\
\hline & Follow-up & $\mathrm{CG}$ & 0.142 & 0.012 & & \\
\hline \multirow{8}{*}{$\begin{array}{l}\vec{Z} \\
0 \\
0 \\
0 \\
0 \\
: \\
0 \\
0 \\
0 \\
0 \\
0 \\
0 \\
0 \\
.00 \\
0 \\
0 \\
0 \\
0\end{array}$} & \multirow{2}{*}{$\begin{array}{l}\text { Knowledge ac- } \\
\text { quiring (1st ap- } \\
\text { plication) }\end{array}$} & $\mathrm{EG}$ & 0.071 & 0.200 & \multirow{2}{*}{18.480} & \multirow{2}{*}{0.076} \\
\hline & & $\mathrm{CG}$ & 0.107 & 0.200 & & \\
\hline & \multirow{2}{*}{$\begin{array}{c}\text { Transfer (1st ap- } \\
\text { plication) }\end{array}$} & $\mathrm{EG}$ & 0.083 & 0.200 & \multirow{2}{*}{3.264} & \multirow{2}{*}{0.073} \\
\hline & & $\mathrm{CG}$ & 0.105 & 0.200 & & \\
\hline & \multirow{2}{*}{$\begin{array}{l}\text { Knowledge ac- } \\
\text { quiring (follow- } \\
\text { up) }\end{array}$} & $\mathrm{EG}$ & 0.099 & 0.058 & \multirow{2}{*}{0.231} & \multirow{2}{*}{0.631} \\
\hline & & $\mathrm{CG}$ & 0.152 & 0.050 & & \\
\hline & \multirow{2}{*}{$\begin{array}{l}\text { Transfer (follow- } \\
\text { up) }\end{array}$} & EG & 0.103 & 0.039 & \multirow{2}{*}{1.430} & \multirow{2}{*}{0.234} \\
\hline & & $\mathrm{CG}$ & 0.096 & 0.200 & & \\
\hline \multirow{8}{*}{ 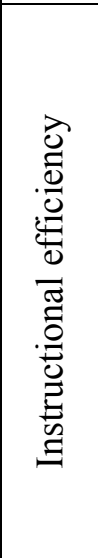 } & \multirow{2}{*}{$\begin{array}{l}\text { Knowledge ac- } \\
\text { quiring (1st ap- } \\
\text { plication) }\end{array}$} & EG & 0.069 & 0.200 & \multirow{2}{*}{0.495} & \multirow{2}{*}{0.483} \\
\hline & & $\mathrm{CG}$ & 0.109 & 0.183 & & \\
\hline & \multirow{2}{*}{$\begin{array}{l}\text { Transfer (1st ap- } \\
\text { plication) }\end{array}$} & EG & 0.076 & 0.200 & \multirow{2}{*}{2.029} & \multirow{2}{*}{0.157} \\
\hline & & $\mathrm{CG}$ & 0.096 & 0.200 & & \\
\hline & Knowledge ac- & EG & 0.081 & 0.200 & & \\
\hline & $\begin{array}{l}\text { up) } \\
\text { upwing (10110w- }\end{array}$ & $\mathrm{CG}$ & 0.089 & 0.200 & 1.840 & $0.1 / 1$ \\
\hline & Transfer (follow- & $\mathrm{EG}$ & 0.077 & 0.200 & 211 & 610 \\
\hline & up) & $\mathrm{CG}$ & 0.075 & 0.200 & 0.212 & 0.042 \\
\hline
\end{tabular}




\section{Biographies}

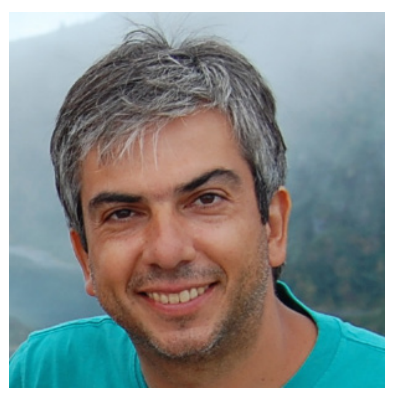

Mário Melo is a Physics teacher in a private secondary school in Lisbon, Portugal. He is finishing his $\mathrm{PhD}$ thesis in Information and Communication Technologies (ICT) in Education in the Institute of Education, Lisbon University. His research is in Instructional Design models, Cognitive Load Theory, multimedia principals and complex learning environments and design of digital educational resources for the teaching of Physics.

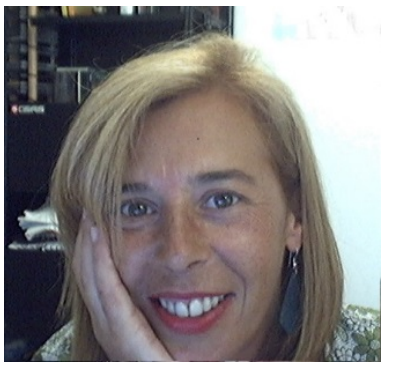

Guilhermina Lobato Miranda, PhD, is a psychologist and assistant professor at the Institute of Education, Lisbon University. She teaches and researches in the domains of educational technology and instructional psychology. She was the main editor (and chapter author) of three books: Educational psychology (2005), Online teaching and multimedia learning (2009), and Psychology of online behavior (2015). She has published several articles mainly in Portuguese journals and some in international journals. 